\title{
On the Universality of Auxiliary Verbs*
}

\author{
Nasser Al-Horais \\ Qassim University, KSA
}

\begin{abstract}
Cross-linguistically, it has often been observed that there is no any specific language-independent formal definition that can be used to determine the characterization of any given element as an auxiliary verb. This paper, though it agrees to some extent with this observation, argues that there is still room to find some universal properties that help us end up with the conclusion that auxiliaries and lexical verbs are two distinct types of syntactic entities. To this end, this paper describes the characteristics
\end{abstract}

\footnotetext{
* I would like to express my deepest gratitude to Qassim University for supporting this work. Here I would like to extend my sincerest thanks and appreciation to the University's Rector Prof. Khalid Al-Humodi, and his Vice-Rectorate for Graduate Studies \& Research: Prof. Abdulrahman Al-Wasel for having created the "right environment" for scientific research in Qassim University. Also, I extend my thanks to Anders Holmberg, Abdelkader Fassi Fehri, Jeffrey Pool, and Maggie Tallerman for insightful comments, suggestions, and discussions on an early version of this paper. I am grateful to Mohammad Al-Moaily for his invaluable help during all phases of this work. Special thanks also go to the anonymous reviewers and editors for clarifying my ideas and for significant editorial improvements which I tried to put to use here. I am solely responsible for any mistakes or inadequacy.
}

Nasser Al-Horais

Arabic Language Department, Qassim University

P.O.Box 6611, Buraidah 51425, Saudi Arabia

Phone: 00966556063595; Email: nasser.alhorais@gamil.com

Received September 6, 2011; Revised November 1, 2011; Accepted November 29, 2011. 
necessary for what is to count as an auxiliary verb. Having done that, the paper turns to illustrate the most common properties that can be found among languages in order to find a clear universally agreed definition of an auxiliary verb.

Keywords: auxiliary verb, lexical verb, morphological information, theta role, negation, structural property, NICE property

\section{Introduction}

Delimiting properties of auxiliary verbs vis à vis lexical verbs has been the topic of continuous debate in generative grammar. It has, as stated by Heine (1993: 26), "provided one of the most popular battlegrounds for disputes of linguistic theory." Although it is quite widely accepted that an auxiliary verb can be defined as "an element that in combination with a lexical verb forms a mono-clausal verb phrase with some degree of (lexical) semantic bleaching that performs some more or less definable grammatical function" (Anderson 2006: 5, cf. Heine 1993: 701), there is, in fact, no agreed formal definition that can be adopted to determine the characterization of any given element as an auxiliary verb. In this regard, Anderson (To Appear, p. 1, n. 3) considers any definition of auxiliary verb as admittedly somewhat nebulous because he strongly believes that:

There is no, and probably cannot be, any specific, language-independent criteria that can be used to determine the characterization of any given element as a

1 Heine (1993: 70) defines auxiliary verb as "an item on the lexical verb to functional affix/particle continuum, which tends to be at least somewhat semantically bleached, and grammaticalized to express one or more of a range of salient verbal categories, most typically aspectual and modal categories, but also not infrequently temporal, negative, or voice categories." 
lexical verb (including in serialized functions) or an auxiliary verb. As in all scalar, gradual, or gradient phenomena, clines of grammaticalization and semantic bleaching will have 'gray areas,' where the element in question has accrued certain features generally associated with end-points or focal points on the continuum, but perhaps not others. It seems likely that the degree of grammaticalization and semantic bleaching deemed sufficient to stop calling some particular verbal element $\mathrm{Xv}$ usages of lexical verb Xlv and start calling it auxiliary verb Xav will vary from researcher to researcher, even when working on the same language.

The problems surrounding the definition of auxiliaries, resulting in not finding a clear universally agreed definition, relate to various reasons. According to Kuteva (2001: 5), one of these reasons is that:

There exists no clear demarcation line between periphrastic verb expressions and bound morphemes-all the more so since one and the same form may often have two different synchronic statuses, as a separate word and as a bound morpheme. Even if the form is readily recognized as a separate word, it will very often be considered by some linguists as a lexical verb and by others as an auxiliary-something which is referred to as the 'amphibian' nature of auxiliaries.

As pointed out above by Anderson, another reason could be derived from the fact that properties of auxiliaries differ from one language to another and hence it is hard to construct a consistent set of criteria to define (and thereby identify) auxiliaries.

This paper mainly aims to address the question of what is to count as an auxiliary verb. More specifically, the current discusses 
the kind of properties which have been taken into account in characterizing the auxiliary class in syntactic theory in order to find crosslinguistic criteria which set auxiliaries verbs apart from lexical verbs.

The current paper is organized as follows. Section 2 considers the grammatical properties distinguishing auxiliaries from lexical verbs by language-independent characteristics. Section 3, by contrast, shows that defining auxiliaries is further complicated by the fact that there are some properties of auxiliaries that are specific to some languages, and do not extend to other languages auxiliaries. This can be seen in English, some Uralic languages (e.g., Finnish), and Tamil. Section 4 concludes the paper, and shows that although it is extremely difficult to decide what a good auxiliary should look like, there is still room to find some universal properties that help us argue that auxiliaries and lexical verbs are two distinct types of syntactic entities.

\section{Some Properties of Auxiliaries}

Cross-linguistically, the formal characteristics which delimit auxiliary from lexical verbs can be divided into two types: structural and thematic. Both of these types are different from one language to another, even between languages of the same family. Let us first begin by the structural properties.

\subsection{Structural Properties}

One of the most distinguishing structural properties of verbs which can function as auxiliary verbs is that auxiliaries are strongly associated with verbal rather than with nominal elements of a sentence. "They 'fill out' add to or further specify the predicate rather than its arguments" (Berman 1980: 17). Accordingly, it has been argued that auxiliaries must be in combination with a 
lexical verb, forming a mono-clausal verb phrase (Anderson 2006: 5 ). This can be noticeably seen in a number of languages such as Korean (1), Tamil (2), and Khalkha Mongolian2 (3) where, in these languages, no element can intervene between the auxiliary and the lexical verb.

(1) a. John-un chayk-ul ppali ilk-e peli-ess-ta. John-Top book-Acc quickly read throw away-Past-Decl "John quickly completed reading a book."

b. *John-un chayk-ul ilk-e ppali peli-ess-ta. John-Top book-Acc read quickly throw away-Past-Decl (Suh 2000: 107)

(2)

a. avan porudkal-ai vāyki mudi-t-t-ān. he-Nom groceries-Acc bought-Inf has-Perf-3ms "He has bought groceries."

b. *avan vānki porudkal-ai mudi-t-t-ān. he-Nom bough-Inf groceries-Acc has-Perf-3ms [Thanks to Mohana Ramasamy for the Tamil data.]

(3)
a. Egॅ̌
nom unś-an.
elder:sister book read-NPast
"The elder sister reads a book."

2 In the interests of consistency, some of the examples are reproduced in this paper in a form slightly different from that in which they appear in the sources cited. Abbreviations used in this paper are as follows:

1, 2, 3-first, second, third person; Acc-accusative; Aux-auxiliary; Connconnective ending; Decl-Declarative; f-feminine; Fut-future; Gen-genitive; Indic -Indicative; Inf-infinitive; m-Masculine; Neg-Negative; Nom-nominative; NPNoun Phrase; p-Plural; PastPart-Past Participle; Part-Particle; Perf-perfective; Pot-Potential; Pres-Present; s-singular; $t A$-Infinitive with-tA(non-finite verb morphology in Finnish); Top-topic; V-verb 
12 On the Universality of Auxiliary Verbs

b. Egč nom unś-ij bai-na. elder:sister book read-Conn be-NPast "The elder sister is reading a book."

c. Ehč nom unś-aad bai-na. elder:sister book read-Conn be-NPast "The elder sister keeps reading a book."

d. Egč nom unś-ij gar-na. elder:sister book read-Conn get:out-NPast "The elder sister begins to read a book." (Kwon 1998: 2)

The puzzling fact, however, is that this conclusion cannot be generalized to other languages. In Arabic and Hebrew; for example, the subject occurring between the auxiliary and the lexical verb is marked but still grammatical. Hence, the two verbs don't form a compound structure as shown in (4) for Arabic and (5) for Hebrew.

(4) a. ?Sbaha-t hind-un ta-takalam-u 1-engeliziat-a. become.3fs Hind-Nom 3fs.speak-indic the-English-Gen (Intended) "Hind has started to speak English."

b.hind-un ?aSbaha-t ta-takalam-u 1-engeliziat-a. Hind-Nom become.3fs 3 fs.speak-indic the-English-Gen (Al-Horais 2009: 93)

(5) Be yaldut-o

haya

Eli poter

in childhood-his would.Past.3ms

Eli solve.Part.3ms

targil-ey

matemática

be

kalut.

exercises

mathematics in

ease 
"In his childhood, Eli would solve math exercises easily." (Falk 2004: 242)

More complicatedly, the two different pictures can be found in a single language family such as Romance languages. In Romanian, for instance, the auxiliary and the lexical verb have an internal hierarchical structure and thus they must be in monoclausal relation. According to Monachesi (2005), Romanian does not present any construction in which the subject or the verbal complements can intervene between the auxiliary and the lexical verb as illustrated in (6) and (7), taken from Monachesi (2005: 137).

(6) a. Mama a fãcut o prăjitură. mum has made a cake "Mum has made a cake."

b. *A mama făcut o prăjitură. has mum made a cake (Intended) "Mum has made a cake."

(7) *Am filme bune văzut. have films good seen

"I have often seen good films."

In each of these examples, the auxiliary and the lexical verb in Romanian form a unit which cannot be separated by other elements. Hence, it seems that the two verbs are in the compound structure (8), not flat structure (9), and hence the former is the most appropriate to capture auxiliary verb constructions in Romanian (see Monachesi 2005: 102). 
14 On the Universality of Auxiliary Verbs

(8)

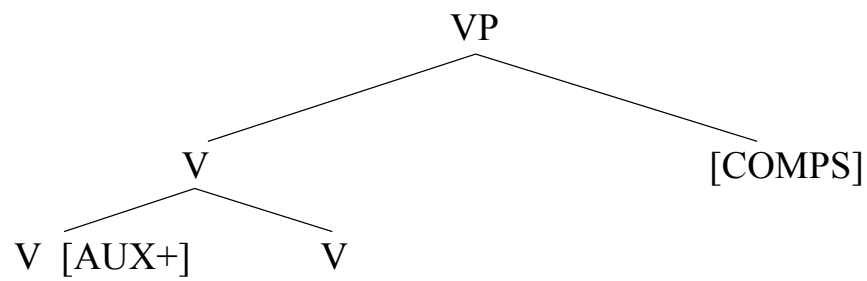

(9)

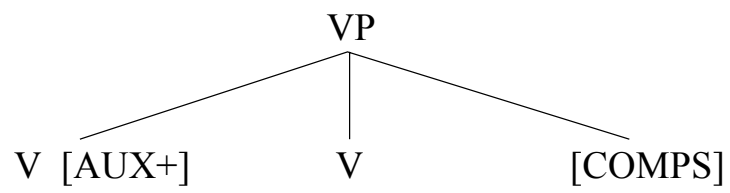

The situation is different in Italian where subject can occur between the auxiliary and the lexical verb. ${ }^{3}$ This can be shown by the following example in (10):

(10) Avendo Martina deciso di partire, possiamo usare having Martina decided to leave, can use la sua stanza.

the her room

"Martina having decided to leave, we can use her room." (Monachesi 2005: 137)

The same behaviour is observed with French auxiliaries in which subject clitics can occur between the auxiliary and the lexical verb, as shown by the subject clitic $t u$ in (11):

3 One of the anonymous reviewers pointed out that in Italian, it is not only the subjects that can occur between the auxiliary and the lexical verb, but also other elements like adverbs also can do so. S/he cited the following example:

Io ho semplicemente deciso così.

I have simply decided so 


\section{(11) L'as-tu mange? \\ it have-you eaten \\ "Have you eaten it?" (Monachesi 2005: 137)}

Interestingly enough, in some languages, like Korean, auxiliary verb constructions can be formed with a lexical verb followed by more than one auxiliary verb. Consider the following examples, taken from Yoo (2003: 414):

a. Nay-ka sakwa-lul mek-nun-ta.

I-Nom apple-Acc eat-Pres-Decl

"I eat an apple."

b. Nay-ka sakwa-lul mek-e po-ass-ta.

I-Nom apple-Acc eat do.as.a.try-Past-Decl

"I tried to eat an apple."

c. Nay-ka sakwa-lul mek-e po-ci anh-key

I-Nom apple-Acc eat do.as.a.try not

toy-ess-ta.

come.to-Past-Decl

(Lit.) "I came to not try to eat an apple."

Another debatable property of the auxiliary verb comes from the observation that auxiliary verbs can occur as main verbs (Conrad 1988: 92). For example, the typical two English auxiliary verb have and be can function as a lexical verb4 as in (13b) and (14b). The same behavior can be observed in the Arabic auxiliary verb kaana as in (15b), but not in the other Arabic auxiliaries as

4 By contrast, 'get' does not have the properties that English auxiliaries are supposed to have. It doesn't have the NICE properties (see section 4), and hence it is labelled a 'lexical verb.' For more discussion about 'get,' see Haegeman (1985), Fleisher (2006). 
exemplified in (16) below.

(13) a. I don't have enough money. (AUXILIARY have)

b. I have not enough money. (LEXICAL have, see Collins 2009: 12)

(14) a. She is waiting. (AUXILIARY be)

b. She is a doctor. (COPULAR be, a lexical verb) (Payne 2011: 262)

(15)

a. kaana ahmad-u taajir-an.

was.3ms Ahmad-Nom tradesman-Acc

"Ahmad was a tradesman."

b. kaana taajir-un.

existed. $3 \mathrm{~ms}$ tradesman-un

"There existed a tradesman." (El-Rakhawi 1982: 260)

(16) a. kaada-t hind-un ta-njah-u fii

[almost]5-3f Hind-Nom 3fs-pass-Indic in

1-ixtibar-i.

the-exam-Gen

(Intended) "Hind almost pass the exam."

b. Saara aqalj-u ya-taSaGTu bi-kaqafat-in. started.3ms the-snow-Nom 3m-falling heavily-Gen "The snow started falling heavily."

c. baat-uu ya-tafahamuuna 1-muŜkilat-a. become. $3 \mathrm{mp} \quad 3 \mathrm{~m}$-understand. $3 \mathrm{mp}$ the-problem-Acc (Intended) "They have become aware of the problem." (Al-Horais 2009: 96)

5 I tried to find an equivalent verb in English to the verb kaada, but I couldn't. Therefore, I used the adverb 'almost' to convey the meaning of kaada. 
Another significant structural property of auxiliaries is that of carrying all morphological information. In languages with rich inflectional morphology, auxiliaries carry all morphological information relating to a lexical verb such as person/number agreement, tense, aspect, or mood affixes, leaving a lexical verb in a non-finite participial form. This is best reflected in Finnish as shown in (17), taken from Koskinen (1998: 70).
(17)
a. Hely-n
täyty-y
lähte-ä.
Hely-Gen must-3s leave- $t A$
"Hely must (=has to) leave."
b. Hely-n täyty-i lähte-ä.
Hely-Gen must-Past.3s leave- $t A$
"Hely had to leave."
c. Hely-n täyty-ne-e lähte-ä.
Hely-Gen must-Pot-3s leave- $t A$
"Hely probably has to leave."

In certain languages, like Arabic; a language with a heavily inflectional morphology, both the lexical verb and auxiliary verb carry the same morphological information, in particular, phi-features as shown in (18). A somewhat similar patterning is found in Hebrew, Hindi-Urdu, Manam, ${ }^{6}$ and Persian, as respectively illustrated in (19)-(22), below:

$$
\begin{aligned}
& \text { a. kaan-a ya-ktub-u r-risaalat-a. } \\
& \text { was-3ms 3ms-write-indic the-letter-Acc } \\
& \text { "He was writing the letter." }
\end{aligned}
$$

\footnotetext{
6 Manam is Austronesian language spoken by about 6,000 people on Manam Island (see Turner 1986: 10).
} 
b. hum kaan-uu ya-ktub-uu-na r-risaalat-a. they-Nom were-3mp 3-write-3mp-indic the-letter-Acc "They were writing the letter." (Al-Horais 2009: 97)

(19) Ruti hayta toferet smalot.

Ruti be-Past-3fs sew-fs dresses

"Ruti was sewing/used to sew dresses."

(Shlonsky 1997: 61)

(20) Rahul kitaab parh-taa thaa.

Rahul.m-Nom book.f read-Hab.ms be.Past.ms

"Rahul used to read a/the book." (Bhatt 2005: 759)

(21) ra?a'na ?u-em=ema?-1'-be ?u-so'a?i

what 2-redpl=do-3obj-and 2-aux

"What are you doing?"

(Lichtenberk 1983: 198, as cited in Anderson 2006: 222)

(22) a. Dâšt-am qazâro mi-xord-am.

had-1s. food asp-eat-Past-1s

"I was eating the food."

b. dâr-am qazâro mi-xor-am.

have-1s food asp-eat-Pres-1s

"I am eating the food." (Taleghani 2006: 27-28)

\subsection{Thematic Properties}

One important and perhaps agreed criterion which singles out the auxiliary verb from the lexical verb has to do with argument structure. While the former loses its argument structure, which makes it unable to thematically associate with any of the NPs in the sentence, the latter preserves argument structure, assigning 
thematic theta roles $^{7}$ to the NPs in subject and object position. That is, auxiliary verbs are completely devoid of any argument structure and hence their role in the sentence is only functional, supplying or modifying information about tense, aspect, modality, and polarity (Payne 1985, Heine 1993), and this, as stated by Cowper (1990: 85), is "at least part of what defines as an auxiliary verb."8 This, however, can be precisely seen in all the examples cited above, where the auxiliary verbs there never assign any theta roles to the subjects but contribute only functional information (cf. Pollock 1997: 239, Lasnik 2000).

Being unable to assign a theta role also distinguishes auxiliary verbs constructions from other compound constructions like V1-V2 compound formation $^{9}$ (23-24), light verb constructions ${ }^{10}$ (25), and serial verb constructions 11 (26). In these constructions, the two verbs share the same role in determining the assignment of theta-roles to arguments, ${ }^{12}$ while in auxiliary verbs constructions,

7 In generative grammar, a theta role or $\theta$-role is the formal device for representing syntactic argument structure (the number and type of noun phrases) required syntactically by a particular verb (for more information, see Carine 2006).

8 The same conclusion has been reached by Kenesei (2001: 79). After considering criteria for auxiliaries in Hungarian, she states that "an auxiliary is an independent word that has a complement structure in terms of categories, but has no argument structure, i.e., a capacity to assign thematic roles."

9 Both V1 and V2 are lexical verbs, and hence they assign a theta role to their shared object. For more discussion about this phenomenon, see Fukushima (2008).

10 Light verb constructions are constructions in which an active/patient-denoting verbal noun or adjective combines with a member of a very restricted class of verbs to form a compound verb (Han \& Rambow 2000).

11 As defined by Johnson (2006: 40), "Serial Verb Constructions consist of two verbs (or verb phrases) that occur in sequence without an intervening conjunction (subordinating or coordinating) between the verbs." Baker (1989) provides an analysis of serial verbs in which is often criticized for only accounting for serial verbs which share their objects. Shared objecthood, however, is a defining feature for serial verbs, and hence they must determine theta-role assignment.

12 As for light verbs, there is disagreement among syntacticians regarding whether 
the auxiliaries play no part in determining the assignment of thematic roles to arguments.

(23) a. Ken-ga musuko-o nade-sobire-ta.

Ken-Nom son-Acc stroke-fail-Past

"Ken failed to stroke his son."

b. Ken-ga musuko-o nade-mawasi-ta.

Ken-Nom son-Acc stroke-fondle-Past

"Ken caressed his son."

(Japanese, Hashimoto \& Bond 2005: 146)

(24)

a. Taro-nun yek-e kele-kass-ta.

Taro-Top station-Goal walk-go-Past

"Taro walked to the station."

b. Taro-nun yek-e tallye-kass-ta.

Taro-Top station-Goal run-go-Past

"Taro ran to the station." (Korean, Tanaka 2002: 422)

(25)

a. mwulka-ka halak-i TOY-ess-ta. ${ }^{13}$

price-Nom drop-Nom BECOME-Past

"Prices went down."

b. sintaylywuk-i Columbus-ey-uyhay palkyen-i

new continent-Nom Columbus-by discovery-Nom

TOY-ess-ta.

BECOME-Past

light verbs determine theta-role assignment or not. For a discussion about this issue, see Han \& Rambow (2000), Bowern (2004), Seiss (2009).

13 As illustrated by Sato (1993), the Korean light verb toyta 'BECOME' can only occur in light verb constructions with theme subjects. For more discussion about the role of light verbs in determining theta-role assignment, see Sells (1989), Seiss (2009). 
"America was discovered by Columbus./America became discovered by Columbus." (Korean, Sato 1993)

(26)

a. i bai klos gi im pikin.

he buy clothes give his child

"He bought some clothes which he gave to his child."

b. a tek $\mathrm{n}_{\delta} \mathrm{f}$ kut di bred.

I take knife cut the bread

"I cut the bread with a knife."

(Krio, 14 Finney 2004, cited in Johnson 2006: 40)

\section{Language Specific Properties}

As shown above, recognizing a class of auxiliaries distinct from lexical verbs can be distinguished by language-independent characteristics that look very different in different languages. In this section, I illustrate that this recognition can be distinguished also by language specific properties.

In Tamil and some Uralic languages like Finnish, for example, negation is uttered by a negative marker functioning as an auxiliary verb, while in English the division between auxiliaries and lexical verbs seems relatively clear-cut by using morphosyntactic "tests" for distinguishing both classes from each other (i.e., auxiliaries have the NICE properties, while lexical verbs do not). These tests involve four syntactic properties deemed the NICE properties $^{15}$ by Huddleston (1980: 333, see also Huddleston \& Pullum 2002: 92-112). In the following, I explain these specific properties.

14 Krio is the most widely spoken language in Sierra Leone (Simpson 2008).

15 NICE is an acronym for Negation, Inversion, Code, and Emphasis. 


\subsection{Auxiliation and Negation}

Cross-linguistically, it has been observed that some certain languages negate a clause via a negative marker which has the properties of a finite auxiliary followed by a lexical verb in a non-finite participial form. This is best reflected in Finnish and Tamil, in which a negative marker is an auxiliary verb.

\subsubsection{Finnish}

In Finnish, negative sentences verbal categories are expressed on a negative auxiliary while the lexical verb is expressed in some non-finite form (Sulkala \& Karjalainen 1992, Koskinen 1998). The most common negative marker in Finnish is the negation word e-, which functions as an auxiliary verb, carrying the finite person/number agreement marking which in affirmative sentences is attached to the main verb as previously exemplified in (17). More interestingly, the negative never bears voice or finite tense or mood morphology, all of which always appear on the main verb. The negation can combine with all tenses and moods (except the past tense form, using the perfect participle instead) (Sulkala \& Karjalainen 1992, Koskinen 1998). The following data, in which e- in bold, demonstrate this interesting strategy of expressing sentential negation in Finnish:

(27) e-n osta talo-a.

neg-1s buy house-Part

"I do not buy a/the house." (Miestamo 2000: 66)

(28) Minä e-n lue.

I.Nom neg-1s read

“I'm not reading./I don't read." (Koskinen 1998: 69) 
(29) Kerron ett-e-t puhu suomea.

say-1s that-neg-2s speak Finnish

"I say that you don't speak Finnish." (Mitchell 2006: 231)

(30) Hän e-i tul-lut.

$\mathrm{s} / \mathrm{he}$ neg-3s come-Past-Part

"S/he didn't come." (ibid.)

\subsubsection{Tamil}

As explained in Steever (2000: 107-108), negation in Tamil 16 is expressed in two ways. The first one is morphological negation in which the negative marker $\bar{a}$-, exemplified in (31), is a part of the derivational morphology of the verb. The second one, which is relevant to our discussion here, is syntactic negation expressed by two negative auxiliary verbs: illai and matt. The former is only compatible with present and past tense interpretation as shown in (32), whereas the latter is only compatible with the future tense interpretation as in (33). All the examples below are taken from Steever (2000: 108).

(31) katitam inke var- $\bar{a}$-tu.
letter-Nom here come-neg-es
"The letter will not come here."

(32) avan vara.v illai.

he-Nom come-Inf neg

"He did/does not come."

16 Tamil is a southern Dravidian language. It is spoken mainly in South India. It is the official language in the Indian state of Tamil Nadu. Tamil is also spoken in north-western Sri Lanka, but the kind of Tamil spoken there is slightly different from the kind used in South India (Steever 2000: 31). 

(33) avan vara.v mattan. he-Nom come-Inf Fut-neg-3s "He will not come."

Interestingly enough, the gloss in (31) and (32) draws a significant surprising distinction between the two negative auxiliary verbs illai and mātt. While illai does not inflect for the agreement feature, mätt does. It is not clear from Steever (2000) why illai, unlike mātt, does not carry any inflectional element to show at least the agreement feature since the negative is considered as an auxiliary verb produced by a language with quite rich morphological inflections. Such a fact may add more complexity to the question of what a good auxiliary should look like.

\subsection{The NICE Properties of Auxiliaries}

In English, auxiliaries in general are characterized by the NICE properties, by which auxiliary verbs in English are distinguished from lexical verbs. These properties refer to English auxiliaries occurring with negation, inversion, code, and emphatic affirmation. In the following subsections, I explain these properties, relaying on Hauge (2003) (for further discussion about the NICE properties, see Huddleston 1980, Haegeman 1985, Downing 1996, Huddleston \& Pullum 2002, Payne 2011).

\subsubsection{Negation}

As a property unique to English auxiliaries and drawing a dividing line between auxiliaries and main verbs, English auxiliaries have distinct negative forms with the negation (not) undergoing cliticization to form negative auxiliaries such as isn't, haven't, and shouldn't. Consider the following example: 
(34) a. I shouldn't go to London.

b. *I gon't to London.

\subsubsection{Inversion}

The second of the NICE properties is inversion of the auxiliary and the subject in certain types of constructions. The most common type of construction where this occurs is in interrogative sentences, such as (35a). Subject-auxiliary inversion is also found in certain types of conditional adverbial clauses, such as (35b), and with some adverbs (expressing negative meaning) that are in initial position, as in $(35 \mathrm{c})$ :

(35) a. Is the clown coming?

b. Had I known about the appetite of seals, I'd never have shared my lunch.

c. Seldom had they seen such an animal.

By contrast, lexical verbs do not exhibit this property (Payne 2011: 263-264):

(36) a. *Eats she kimchi?

b. *Broke the workers the vase?

c. *What broke the workers? (trying to mean "What did the workers break?")

d. *Where live we?

\subsubsection{Code}

The third NICE characteristic of an auxiliary is code, referring to sentences in which a lexical verb is subsequently picked up by an auxiliary, in a similar manner to a noun being picked up by a pronoun. This is often the case in constructions containing and so. Examples of this are found in (37)-(39), taken from Payne 
(2011: 264). The ungrammatical examples illustrate the fact that lexical verbs do not have this property:

(37) a. I should see the doctor, and so should she.

b. *I saw the doctor, and so saw she.

(38) a. Who should eat kimchi? She should.

b. Who ate kimchi? *She ate.

(39) a. We were eating kimchi, and so was she.

b. *We eat kimchi and so eats she.

\subsubsection{Emphatic Affirmation}

The last NICE property is emphatic affirmation, where stress is on the auxiliary. In English there can be stress on any verbal form for focus purposes. What is particular about stress on the auxiliary is that it is used for emphatic affirmation of a doubtful statement or denial of a negative statement, as can be seen in (40) below.

(40) a. I can come. (You are wrong to think that I cannot come!)

b. We did see them. (You thought we did not see them!) (Hauge 2003: 59)

\section{Conclusions}

A concrete fact can be drawn from the preceding discussion is that variation in the properties of auxiliaries among natural languages is precisely observed and therefore having a universal standard definition of the auxiliary verb seems elusive. Nevertheless, there is still room for arguing that at least two universal properties must co-occur in order to distinguish the 
auxiliary verb from other syntactic categories. (i) Auxiliation should be understood as the development of constructions into markers of tense, agreement, modality, and perhaps aspect. (ii) Auxiliary verbs do not enter into a thematic relation with the arguments in the sentence, leaving this job to the lexical verbs that auxiliaries tend to occur separately from. This may constitute the standard syntactic argument that auxiliaries and lexical verbs are two distinct types of syntactic entities.

\section{References}

Al-Horais, N. 2009. The Syntax of Arabic Negation Marker Laysa. Ph.D Dissertation. Newcastle University.

Anderson, G. 2006. Auxiliary Verb Constructions. Oxford: Oxford University Press. - To Appear. Auxiliary Verb Constructions in Old Turkic and Altai-Sayan Turkic. In M. Erdal (ed.), Studies in Old Turkic Linguistics. Wiesbaden: Harrassowitz.

Baker, M. 1989. Object Sharing and Projection in Serial Verb Constructions. Linguistic Inquiry 20, 513-553.

Berman, R. 1980. On the Category of Auxiliary in Modern Hebrew. Hebrew Annual Review 4, 15-37.

Bhatt, R. 2005. Long Distance Agreement in Hindi-Urdu. Natural Language \& Linguistic Theory 23, 757-807.

Bowern, C. 2004. Bardi Verbal Morphology in Historical Perspective. Ph.D Dissertation. Harvard University.

Carnie, A. 2006. Syntax: A Generative Introduction. Malden, MA: Wiley-Blackwell.

Collins, P. 2009. Modals and Quasi-Modals in English. Amsterdam: Rodopi.

Conrad, R. (ed.) 1988. Lexikon sprachwissenschafticher Termini. Leipzig: VEB Bibliographisches Institut. 
Cowper, E. 1990. Thematic Underspecification: The Case of 'Have.' Ms., University of Toronto.

Downing, A. 1996. The Semantics of Get-Passives. In R. Hasan et al. (eds.), Functional Descriptions 179-205. Amsterdam: John Benjamins.

El-Rakhawi, T. 1982. Aspects of Sentential Negation in Arabic: A Contribution to the Typology of Negation. Ph.D Dissertation. University of Birmingham.

Falk, Y. 2004. The Hebrew Present-Tense Copula as a Mixed Category. In M. Butt \& T. King (eds.), Proceedings of the LFG04 Conference 226-246. Stanford, CA: CSLI Publications. Fleisher, N. 2006. The Origin of Passive 'Get.' English Language and Linguistics 10.2, 225-252.

Fukushima, K. 2008. On the Type-Wise Productivity of Lexical V-V Compounds in Japanese: A Thematic Proto-Role Approach. Gengo Kenkyu 134, 119-140.

Haegeman, L. 1985. The Get-Passive and Bruzio's Generalization. Lingua 66, 53-77.

Han, C. \& O. Rambow. 2000. The Sino-Korean Light Verb Construction and Lexical Argument Structure. Proceedings of the $5^{\text {th }}$ International Workshop on Tree Adjoining Grammars and Related Formalisms 221-226. Universite Paris 7.

Hashimoto, C. \& F. Bond. 2005. A Computational Treatment of $\mathrm{V}-\mathrm{V}$ Compounds in Japanese. In S. Muller (ed.), Proceedings of the $12^{\text {th }}$ International Conference on Head-Driven Phrase Structure Grammar 143-156. University of Lisbon.

Hauge, H. 2003. Towards a Unified Representation of English and Norwegian Auxiliaries. Nordic Journal of English Studies 2.1, 53-74.

Heine, B. 1993. Auxiliaries, Cognitive Forces, and Grammaticalization. New York: Oxford University Press.

Huddleston, R. 1980. On Palmer's Defense of the Distinction between Auxiliaries and Main Verbs. Lingua 50, 101-115. Huddleston, R. \& G. Pullum. 2002. The Cambridge Grammar of 
the English Language. Cambridge: Cambridge University Press. Johnson, S. 2006. Revisiting the Structure of Serial Verb Constructions. LSO Working Papers in Linguistics 6, 39-48. Kenesei, I. 2001. Criteria for Auxiliaries in Hungarian. In I.

Kenesei (ed.), Argument Structure in Hungarian 73-106. Budapest: Akadémiai Kiadó.

Koskinen, P. 1998. Features and Categories: Non-Finite Constructions in Finnish. Ph.D Dissertation. University of Toronto.

Kuteva, T. 2001. Auxiliation: An Enquiry into the Nature of Grammaticalization. Oxford: Oxford University Press.

Kwon, J. 1998. Auxiliary Verb Constructions in Korean and Khalkha Mongolian. Paper Presented at the $3^{\text {rd }}$ International Symposium on Mongolology 17-24. Inner Mongolia University. Lasnik, H. 2000. Syntactic Structures Revisited: Contemporary Lectures on Classic Transformational Theory. Cambridge, MA: MIT Press.

Miestamo, M. 2000. Towards a Typology of Standard Negation. Nordic Journal of Linguistics 23.1, 65-88.

Mitchell, E. 2006. The Morpho-Syntax of Negation and the Positions of $\mathrm{NegP}$ in the Finno-Ugric Languages. Lingua 116.3, 228-244.

Monachesi, P. 2005. The Verbal Complex in Romance: A Case Study in Grammatical Interfaces. Oxford: Oxford University Press.

Payne, J. 1985. Negation. In T. Shopen (ed.), Language Typology and Syntactic Description: Volume I, Clause Structure 197-242. Cambridge: Cambridge University Press.

Payne, T. 2011. Understanding English Grammar: A Linguistic Introduction. Cambridge: Cambridge University Press.

Pollock, J-Y. 1997. Notes on Clause Structure. In L. Haegeman (ed.), Elements of Grammar: A Handbook of Generative Syntax 237-279. Dordrecht: Kluwer.

Sato, Y. 1993. Complex Predicate Formation with Verbal Nouns in Japanese and Korean: Argument Transfer at LF. Ph.D 
Dissertation. University of Hawaii.

Seiss, M. 2009. On the Difference between Auxiliaries, Serial Verbs, and Light Verbs. In M. Butt \& T. King (eds.), Proceedings of the LFG09 Conference 501-519. Stanford, CA: CSLI Publications.

Sells, P. 1989. More on Light Verbs and Theta-Marking. Ms., Stanford University.

Shlonsky, U. 1997. Clause Structure and Word Order in Hebrew and Arabic: An Essay in Comparative Semitic Syntax. Oxford \& New York: Oxford University Press.

Simpson, A. 2008. Language and National Identity in Africa. Oxford: Oxford University Press.

Steever, S. 2000. The Tamil Auxiliary Verb System. London \& New York: Routledge.

Suh, Y. 2000. A Study of the Auxiliary Verb Construction and Verb Serialization in Korean. Ph.D Dissertation. University of Washington.

Sulkala, H. \& M. Karjalainen. 1992. Finnish. London \& New York: Routledge.

Taleghani, A. 2006. The Interaction of Modality, Aspect, and Negation in Persian. Ph.D Dissertation. Arizona University.

Tanaka, E. 2002. A Japanese Compound Verb V-te-iku and Event Structure. Proceedings of Pacific Asia Conference on Language and Computation 16, 421-432.

Turner, B. 1986. A Teaching Grammar of the Manam Language. Ukarumpa: Summer Institute of Linguistics.

Yoo, E-J. 2003. Case Marking in Korean Auxiliary Verb Constructions. Proceedings of the $9^{\text {th }}$ International Conference on HPSG 413-438. Stanford University. 